\title{
The temperature of ingested water: Its effect on body temperature
}

\author{
EDWARD DEAUX and ROBERT ENGSTROM \\ Antioch College. Yellow Springs. Ohio 45387
}

\begin{abstract}
The ingestion of water of different temperatures was found to have a pronounced effect on body temperature in rats. Drinking $12^{\circ}$ and $24^{\circ} \mathrm{C}$ water led to sharp decreases in body temperature of as large as $1.2^{\circ} \mathrm{C}$, and, when free access to the water was given, recovery failed to occur within the 20 -min test period. The results are related to mechanisms of preabsorptive satiety.
\end{abstract}

Water-restriction schedules are hinuwii to lead to self-imposed starvation in rats, with the consequence that water intake is decreased relative to nondeprived rats when water is again made available, and animals may stop drinking before complete absorption of water has taken place. This "preabsorptive satiety" has led to the hypothesis of phase advance mechanisms in the thirst control system, but even though temperature has been mentioned as a variable in this phenomenon (see Fitzsimons, 1972), little attention has been paid to the relationship between the temperature of ingested water and the amount that is consumed. Recently, however, Kapatos and Gold (1972) found that rats kept on a water-restriction schedule, on which they received a 30-min daily exposure to water in the absence of food and 23.5-h access to food alone, showed a significant increase in water intake as the temperature of the available water was raised from $12^{\circ}$ to $36^{\circ} \mathrm{C}$. This implies a relationship between the need for water, the temperature of the water which is ingested as a result of that need, and the need's reduction-a relationship which Kapatos and Gold hypothesize to be mediated by the effects of tongue cooling during drinking. The purpose of this report is to present evidence that the changes which accompany the ingestion of water of different temperatures are of much greater magnitude and of longer lasting consequences than the peripheral effects of tongue cooling.

\section{METHOD}

\section{Subjects}

The Ss were 12 male Holtzman albino rats, averaging 180 days of age and $305 \mathrm{~g}$ of body weight. All animals were housed individually and had free access to Purina Lab Chow. Ambient temperature was kept at $24^{\circ} \pm 1^{\circ} \mathrm{C}$.

\section{Apparatus and Procedure}

The rats were maintained in their home cages on a $23.5-\mathrm{h}$ water-deprivation schedule; $24^{\circ} \mathrm{C}$ distilled water was made available for $30 \mathrm{~min}$ at the same time every day. On testing days, a rat was removed and placed in a test cage (of identical conditions) for at least $10 \mathrm{~min}$. A rectal thermistor probe (Yellow Springs Instrument Model 402) was then inserted to a depth of $6.5 \mathrm{~cm}$. and body temperature was monitored by a
Yeilow Springs instrument Miodei 45 teie thermometer, readabie to $0.01^{\circ} \mathrm{C}$. After at least $10 \mathrm{~min}$, during which a stable baseline temperature was reached, the animal was presented water at one of three temperatures. $12^{\circ}, 24^{\circ}$ (room temperature), and $37^{\circ} \mathrm{C}$ (approximately body temperature). The body-temperature measurements continued for $20 \mathrm{~min}$ after the beginning of water ingestion.

The manner in which water presentation was made varied according to one of three conditions. In Condition W-NF, the rats received free access to water, provided by an insulated bottle and drinking tube affixed to the front of its cage, and no food was available for the 20-min exposure period. In Condition W-F, the rats received water as in the previous condition, but Purina Lab Chow was also available in the test cage. In Condition LW-F, food was also available, but water intake was limited; each animal received two $4-\mathrm{ml}$ portions of water, presented sequentially in a small cup mounted in the cage. In all conditions, the animal's behavior was recorded along with body temperature.

\section{RESULTS}

Due to difficulties involved in monitoring unrestrained rats with a rectal probe, it was not possible to complete every attempted test. Probe shifting, overactivity in the rats, and an occasional bite through the wire caused the abortion of several runs. However, in all, three tests were successfully completed at each of the three temperatures, giving a total of 27 temperature curves. Each set is plotted by $30-\mathrm{sec}$ intervals, with changes shown relative to the baseline body temperature established before water presentation. Both drinking and eating (in Conditions W-F and LW-F) are indicated; during "nonconsummatory behavior" the rats were grooming or generally ambient.

The set from Condition W-NF is presented in Fig. 1. It can be readily seen that drinking $24^{\circ}$ or $12^{\circ} \mathrm{C}$ water produces a rapid, drastic decline in body temperature, the magnitude of which is related to the water temperature. Perhaps even more important is the fact that the body temperature does not recover to its baseline level within the $20-\mathrm{min}$ observation period. When the animals received $37^{\circ} \mathrm{C}$ water, the changes were never greater than $0.25^{\circ} \mathrm{C}$ from baseline.

Condition W.F, shown in Fig. 2, produced results which were similar to those in Condition W-NF, even though food was available and eating occurred. The 

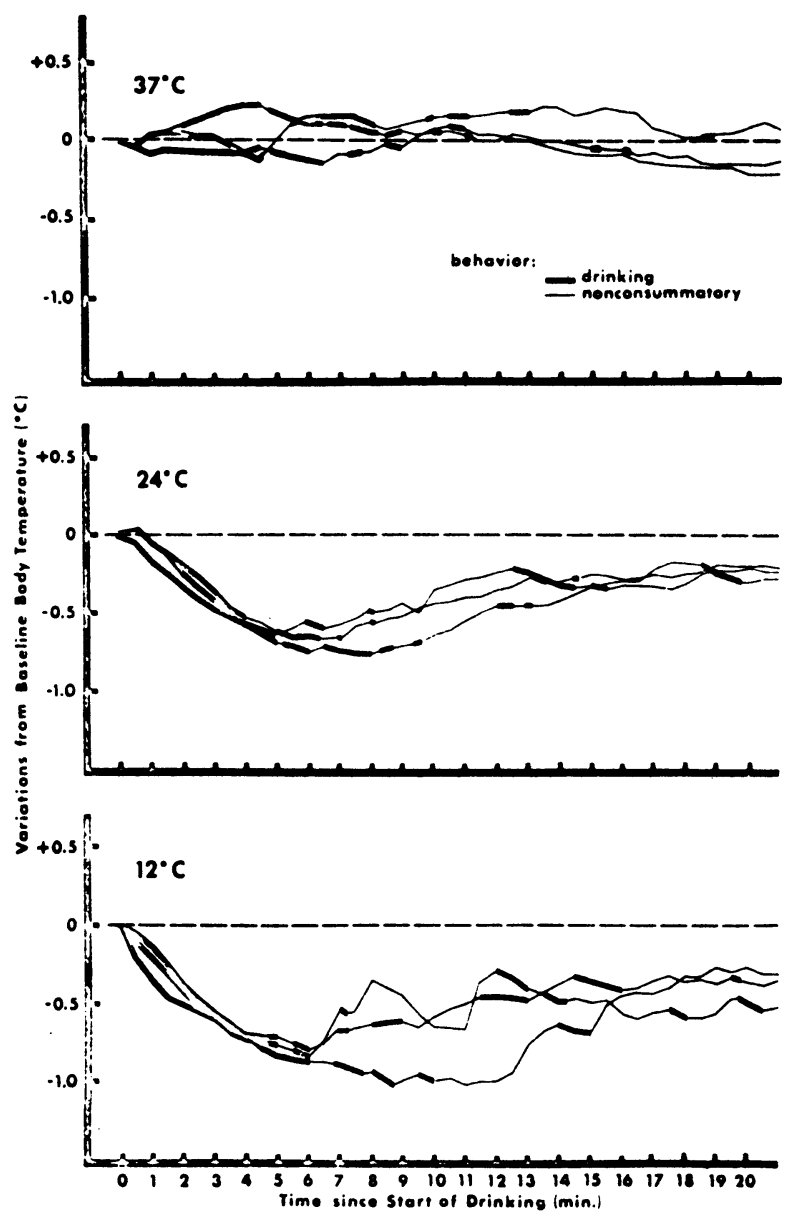

Fig. 1. Condition W-NF: Changes in body temperature, relative to baseline, during a 20 -min period of exposure to distilled water at $37^{\circ}$ (top panel), $24^{\circ}$ (center panel), and $12^{\circ} \mathrm{C}$ (lower panel) in the absence of food. Drinking and nonconsummatory behavior are indicated.

speed and degree of the decline in body temperature is nearly identical to that shown in Fig. 1, as it should have been since the treatment of the animals was the same at that point. However, the recovery was more dependent upon the temperature of the water than it was in Condition W-NF. After drinking $24^{\circ} \mathrm{C}$ water, none of the animals returned to their baseline temperatures by the end of the observation period. In fact, the body-temperature curves remain at a lower level than those shown in Fig. 1, despite regular eating throughout the session.

In Condition LW.F, the initial drop in body temperature was shorter in duration, though somewhat greater in rate, as shown in Fig. 3. Recovery to baseline occurred after ingestion of both $24^{\circ}$ and $12^{\circ} \mathrm{C}$ water, and, as in the first two conditions, the ingestion of $37^{\circ} \mathrm{C}$ water did not lead to any systematic change in body temperature.

The animals in Condition LW.F were given a fixed volume of $8 \mathrm{ml}$, but in the other conditions. the amount consumed was a S-determined variable. In Condition W.NF, the mean water intake was 18.3, 20.1, $27.1 \mathrm{~g}$ for $12^{\circ}, 24^{\circ}$, and $37^{\circ} \mathrm{C}$, respectively. Although the overall difference between the means was not significant, the linear comparison was $(F$ linear $=6.33$, $\mathrm{df}=1 / 6, \mathrm{p}<.05)$. Water-intake data from Condition W-F were not as orderly; the means for the three temperatures, in ascending order, were 18.3, 20.3, and $20.6 \mathrm{~g}$. The difference between groups was not significant, nor was the linear trend.

\section{DISCUSSION}

It is clear from the results that the core body temperature of rats changes rapidly and drastically within minutes of the start of drinking cold or room-temperature water. Furthermore, when water was available throughout the test period and food was not, body temperature did not recover to its original baseline

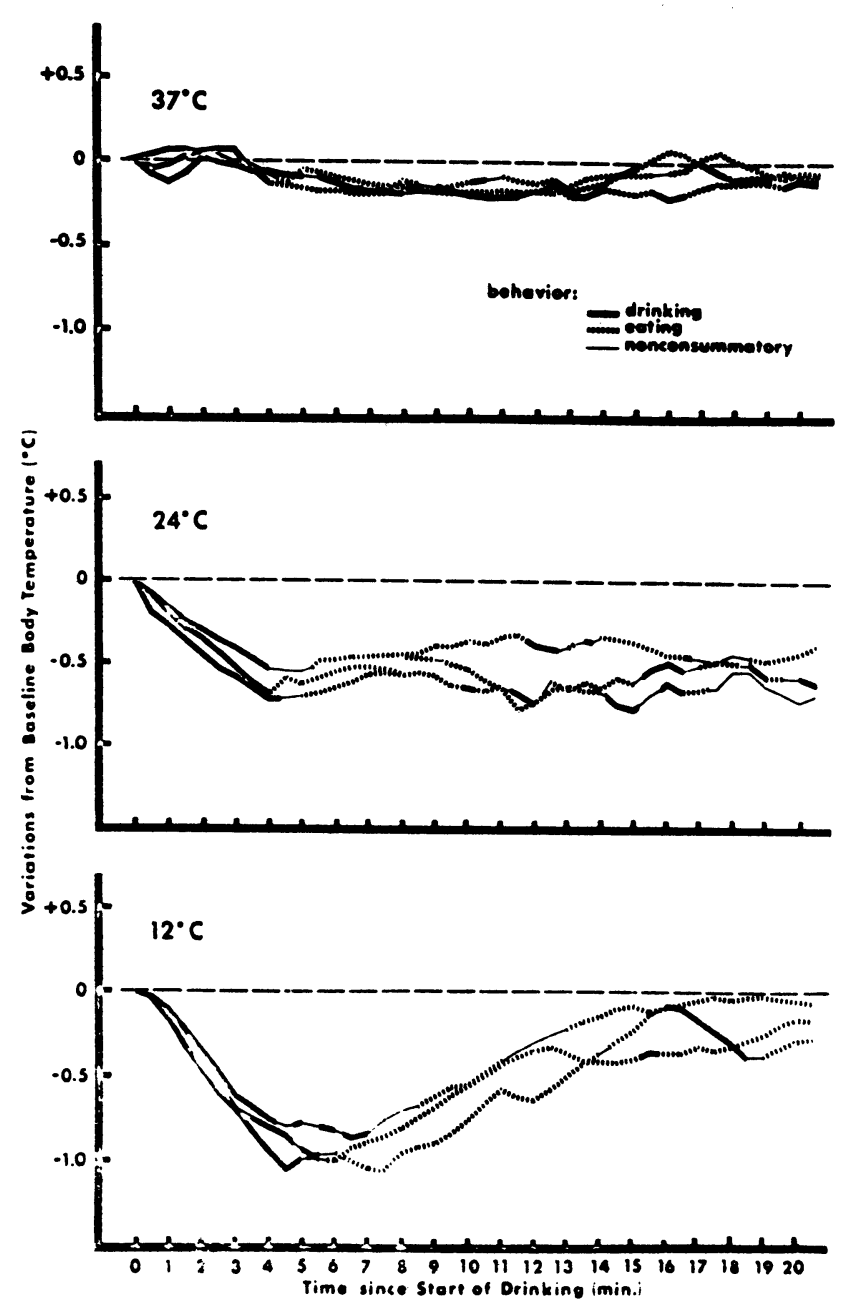

Fig. 2. Condition W-F: Body temperature changes during exposure to distilled water of three different temperatures with food present. Drinking. eating, and nonconsummatory behavior are indicated. 


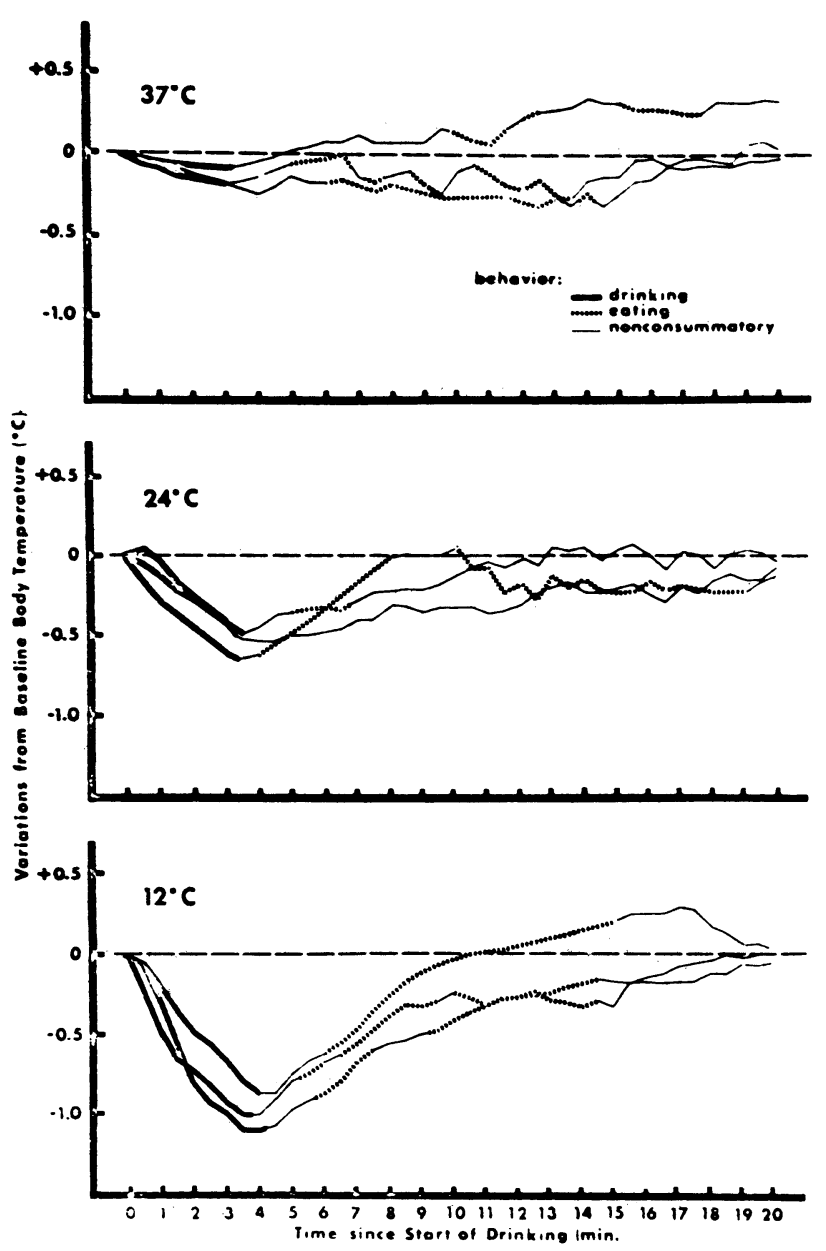

Fig. 3. Condition LW-F: Body temperature measures following the presentation of $8 \mathrm{ml}$ of distilled water of three different temperatures in the presence of food.

within the 20 -min period. The consumption data reveal that animals kept on a 23.5 -h water-restriction schedule tend to drink less cold water than they do body-temperature water, but when food is available during their water-exposure period, the difference is not clear. Also unclear is an explanation for the finding that when food was available, the body temperature recovered from an initial decrease of about $1.0^{\circ} \mathrm{C}$ during the ingestion of $12^{\circ} \mathrm{C}$ water, but the $0.6^{\circ} \mathrm{C}$ decrease resulting from the $24^{\circ} \mathrm{C}$ water did not recover.

Given the marked changes in temperature which occur in the core of the animal, basic mechanisms to explain temperature-dependent ingestion avail themselves. and explanations which rely on tongue cooling or the activation of tongue receptors appear unnecessary. It is just as conceivable that a rat drinks less cold water during a limited exposure period in order to prevent an excessive lowering of its body temperature as it is that it drinks less because its tongue is cool. Weiss and Laties (1961) have demonstrated thermoregulation through adjustive behavior in rats and the cessation of drinking to reverse a rapidly decreasing body temperature would qualiiy as such an aujustive response. It is likewise possible that lowering the temperature of the internal system affects the passage of water from the stomach to the gut and finally into the blood. Hatton and Bennett (1970) have hypothesized that thirst satiation is cued by osmotic changes, and if temperature influences the shifts in body-fluid osmolality that normally accompany water ingestion (Deaux \& Kakolewski, 1971), it follows that osmotic differences could mediate differences in water ingestion.

We feel that for the search for the mediational mechanisms involved in "preabsorptive satiety" and the influence of water temperature on ingestion to be fruitful, it should center on internal or central processes rather than peripheral and presumably short-term events-such as tongue cooling.

\section{REFERENCES}

Deaux, E., \& Kakolewski, J. W. The character of osmotic changes resulting in the initiation of eating, Journal of Comparative \& Physiological Psychology, 1971, 74, 248-253.

Fitzsimons, J. T. Thirst. Physiological Reviews, 1972, 52, 468-561.

Hatton, G. I., \& Bennett, T. Satiation of thirst and termination of drinking: Roles of plasma osmolality and absorption. Physiology \& Behavior, 1970, 5, 479-487.

Kapatos, G., \& Gold, R. M. Tongue cooling during drinking: A regulator of water intake in rats. Science, 1972, 176. 685-686.

Weiss, B., \& Laties, V. G. Behavioral thermoregulation. Science, $1961,133,1338-1343$.

(Received for publication December 1, 1972; accepted January 10, 1973.) 